Research, part of a Special Feature on Scale and Governance

\title{
From Scaling to Governance of the Land System: Bridging Ecological and Economic Perspectives
}

\author{
$\underline{\text { Tom Veldkamp }}^{1}, \underline{\text { Nico Polman }}^{2}, \underline{\text { Stijn Reinhard }}^{2}$, and Maja Slingerland $^{3}$
}

\begin{abstract}
One of the main unresolved problems in policy making is the step from scale issues to effective governance. What is appropriate for a lower level, such as a region or location, might be considered undesirable at a global scale. Linking scaling to governance is an important issue for the improvement of current environmental management and policies. Whereas social-ecological science tends to focus on adaptive behavior and aspects of spatial ecological data, new institutional economics focuses more on levels in institutional scales and temporal dimensions. Consequently, both disciplines perceive different scaling challenges while aiming at a similar improvement of effective governance. We propose that future research needs to focus on four themes: (1) How to combine spatial properties such as extent and grain with the economic units of market and agent; (2) How to combine the different governance instruments proposed by both perspectives; (3) How to communicate the different scaling perspectives (hierarchy vs. no hierarchy) and meanings to policy makers and other stakeholders; and (4) How to deal with the nonequilibrium conditions in the real world and the disciplinary perspectives. Here, we hypothesize that a combined system perspective of both disciplines will improve our understanding of the missing link between scaling and governance.
\end{abstract}

Key Words: combined system perspective; governance; new institutional economics; scaling; socialecological sciences;

\section{INTRODUCTION}

Society has recently experienced a number of severe shocks, such as the excessive rise in food and oil prices, which have led to massive hungerespecially in developing countries — and the crises in financial institutions that have put many people in industrialized countries out of jobs and even out of their houses. With the prospect of global climate change already leading in the short term to more disruptive climatic events affecting both industrial and developing countries, it is urgent that we study systems, their dynamics, and their governance options (Ostrom et al. 2007, Berkes et al. 2009).

With the change from a hunting and gathering society to an agricultural society, the impact of human actions and decisions has increased from the local to larger areas and ecosystems (Goudsblom and Vries 2002, Cumming et al. 2006). System approaches describe the world as a highly dynamic and connected complex system. In recent decades, researchers have recognized the need to incorporate humans into the concept of complex systems, leading to the notion of coupled humanenvironmental systems. Central to this concept is the human factor as the main driving and modifying force of current land-system dynamics (Geoghegan et al. 1998). The "land system" refers to the globalscale, coupled, socioenvironmental system. It includes land use, land cover, and ecosystems and is a very scale-sensitive system, implying that empirical research is heavily influenced by the spatial and temporal scales investigated (Global Land Project (GLP) 2005).

Policies have many unforeseen impacts on (agro) ecosystems at different levels of spatial and temporal scales. For example, it has been argued that the EU decision to stimulate biofuel production to decrease global climate change leads to competition for resources to raise fuel crops vs. food 
crops, contributing to an increase in global food prices that affects local poor urban populations in developing countries (Boddiger 2007), and stimulates farmers to overexploit natural resources to make a living. Apart from these direct links between policy and (agro)ecosystems at different spatial scales, often unforeseen temporal consequences in (agro)ecosystems exist that originate in the multiscale interactions within these (agro) ecosystems (Veldkamp et al. 2001, Dalgaard et al. 2003). This observation fits well within a long history of disappointments in policy and management related to our environment (Cash et al. 2006) and indicates that scale-sensitive policies and governance structures are required.

One of the main unresolved problems with policy making is the step from scale issues to governance. What is appropriate for a lower level, such as a region or a location, may be considered undesirable at a global scale and vice versa. Scale can be defined in many ways (Costanza et al. 1993, Costanza et al. 1999, Gibson et al. 2000, Wu and Li 2006), but all definitions refer to quantitative dimensions of a phenomenon defined in space and time. Quite a significant body of literature exists on technical scaling issues (Wu and Li 2006). They are mainly centered around disciplinary research on geography and landscape ecology. Economists, however, often speak about aggregation level instead of scale level (van der Veen and Otter 2003). Related to scale is the notion of levels, which are seen as units of analysis that are located at different positions on a scale continuum. It is thus essential to differentiate between "scale" and "level," following a plea for recognition of scale dependency (Peterson and Parker 1998). Scale dependency leads to changing observed empirical relationships when data are aggregated and analyzed (Turner and O'Neill 1995, De Koning et al. 1998, Kok and Veldkamp 2001), leading to the concept of nested hierarchies in ecology. One of the best known spatial-scale effects of decision making is often referred to as the NIMBY (not in my back yard) behavior of agents at different spatial levels.

This led Cash et al. (2006) to visualize scales and levels as different beads on a chain. Scale is also intimately linked to observation methodology. Different observation techniques of a phenomenon may yield different (not always compatible) system descriptions (Lambin et al. 2001). Apart from observation, postulation can also have a significant scale effect. A related issue is the disciplinary bias often involved in measuring, assuming, and describing systems.

Governance is a contested concept and is defined in various ways. Discussions can for instance be found in political sciences (e.g., Pierre 2000, Rhodes 2007), social-system sciences (e.g., Anderies et al. 2004, Janssen and Anderies 2007), institutional economics (e.g., Williamson 1998, Bowles 2004, Dixit 2004), and ecological economics (e.g., Constanza et al. 1999). This paper contributes to the literature by systematically connecting socialsystem sciences and economic governance as developed within the field of New Institutional Economics (NIE), an economic approach in which other disciplines may play an important role in understanding institutions and their effects on the economy (Joskow 2008, Williamson 1998). Within this tradition, we want to bridge social-system sciences and NIE. Furthermore, institutional economists are aware of the systems orientation of NIE when analyzing institutions (Williamson 1996). More specifically, new institutional economists study the social institutions that bind the economic system (Coase 1978). Examples are firms, markets for goods and services, land markets, capital markets, international trade, and so on. In line with Coase (1978), NIE can be defined by its subject matter, which is the economic system. In this sense, Coase is critical to modern economic analysis (Medema 1995). We believe that our approach contributes to the analysis of economic systems.

A discussion of alternative economic approaches, such as connecting to new economic geography or new social economics, is beyond the scope of this paper. We chose to focus on NIE because it provides ways to analyze governance and coordination of social arrangements. Also, given its systems orientation and interdisciplinary approach, elucidating the connections with NIE seems to be a logical next step. Introducing alternative economic theories would change the focus of the paper at the expense of bridging NIE and social-system sciences.

Effects of scaling on governance have become recognized as an important issue nowadays. Due to the increased global connectivity between levels of spatial scales and cross-scale interactions, new governance structures or modes of governance are warranted to meet the needs of the changing world. In an exploratory paper on scale and cross-scale dynamics, Cash et al. (2006) identified three major 
scale challenges referred to as (1) ignorance, (2) mismatch, and (3) plurality. Ignorance refers to the unknown cross-level and cross-scale interactions that take place. Mismatch is the archetypal scale problem in that human institutions do not usually map coherently with the biophysical scale of the resource in space and time. Plurality refers to the often incorrect assumption that there is a single, correct or best scale or level. The analysis of Cash et al. (2006) was based on a specific set of examples that did not cover all disciplinary perspectives.

In this paper, we explore the scaling governance challenge by comparing landscape ecological and economic perspectives on scale and level. Landscape ecological and economic sciences have different system delineations, quantification principles, processes, and goal orientations. The objective of this paper is to develop a research agenda that can help to effectively bridge the gap between multi-scale landscape ecological system approaches and institutional economics scales via governance. Before we construct the blueprint of such a bridge, we will first build its piers by characterizing the archetypical forms of both paradigms. The main bridge structure will be sketched by analyzing recent developments of both sciences and their common and diverging aspects with regard to governance. Insights from integrating both perspectives will be discussed using a case study on soil protection in the European Union (EU).

\section{FRAMEWORK OF ANALYSIS: LEVELS IN LANDSCAPE ECOLOGY AND ECONOMICS}

The most obvious way to start an analysis of the two different system perspectives and scaling is to study the system properties as used by landscape ecological and economic sciences. To synthesize the main features, we first characterize both paradigms by their archetypes. This necessarily involves discrepancies between the basic representation of the core of both sciences and their state of the art. We demonstrate differences in views and backgrounds before we bridge both approaches through governance. Both sciences have developed over time from their archetypes and have incorporated aspects of governance in their framework. These developments in ecology and economics tend to bring both paradigms closer together.
In environmental sciences, governance is considered to be a response of a socioeconomic system aimed at managing unwanted effects of human actions while taking care of human needs. In this context, governance is seen as an adaptive approach (Folke et al. 2005). The interactions between societies and natural systems create dynamic feedback loops in which humans influence, and are influenced by, natural systems. These dynamic feedback loops generate emergent behavior that cannot be understood through a separate analysis of man and nature (Holling 2001, Kinzig et al. 2006, Walker et al. 2006). The resilience alliance network (http://www.resalliance. org/1.php) has developed its own systems approach: the so-called social-ecological system (SES). A structure composed of a common-pool resource, its users, and an associated governance system is an example of a SES (see Janssen and Anderies (2007)). Almost in parallel, there have been initiatives that focused more on land-use systems, which referred to such systems as coupled humanenvironment systems (HES) (Turner et al. 2007). Both approaches strongly advocate a complex systems approach whereby humans are seen as an element of an hierarchical multi-scale system. In HES and SES, people and ecosystem seem to be seen as part of one system with mutual feedback and feed forwards.

Economic governance can be defined as the processes that support economic activity and economic transactions by protecting property rights, enforcing contracts, and taking collective actions to provide appropriate physical and organizational infrastructures (Dixit 2003). In NIE, a governance structure (institutional arrangement) is an arrangement between economic units that governs the ways in which units can cooperate or compete. This implies that in the NIE context governance structures govern transactions over the short or long term in a formal or informal way. These structures may involve a single individual, a group of individuals cooperating, or the government (alone or in cooperation with others) (Davis and North 1971). The institutional environment mainly defines (or acts as a constraint on) the environment of the institutional arrangements (Williamson 1996).

Social-ecological systems are coupled systems of people and nature (Brand and Jax 2007). Much of the current research is devoted to understanding the coupled system behavior (Westley et al. 2002). 
Most of the work on SES has been done on the amount of disturbance a system can absorb and still remain within the same state or domain of attraction (Folke 2006). A parallel development happened in the Land-Use Cover Change (LUCC) project of the International Geosphere-Biosphere Programme (IGBP; http://www.igbp.net/) under the International Human Dimensions Programme on Global Environmental Change (IHDP; http://www.ihdp.unu. edu/) (Lambin and Geist 2006), which focused on land-use systems. The LUCC community (now GLP) uses a subdivision in socioeconomic and biophysical system components that interacts at different levels. A consequence of such a system view is that effects are considered to cascade up and down in the system, leading to sometimes unforeseen land dynamics (Veldkamp 2009).

There is no "scale theory" in economics-in fact, scale is hardly treated in economic textbooks (Jaeger and Tol 2003, van der Veen and Otter 2003). New institutional economics has provided more realistic approaches than Walrasian economics and models how to deal with imperfect markets and the role of institutions in managing our environment. The central proposition of institutional economics is that institutions matter (see, for instance, Furubotn and Richter 1997, North 2000, Williamson 2000, Ménard 1995). Institutions are the written and unwritten rules, norms, and constraints that humans devise to reduce uncertainty and control their environment (Ménard and Shirley 2005). Also, Williamson (2000) explicitly includes time in his approach on levels of social analysis. The different levels-(1) embeddedness (informal institutions, customs, traditions, norms, and religion), (2) institutional environment (formal rules of the game, i.e., constitutions, laws, and property rights), (3) governance (play of the game, e.g., aligning governance structures with transactions), and (4) resource allocation and employmentchange at different speeds. Embeddedness changes rather slowly compared with resource allocation and employment. Higher levels determine what is feasible at lower levels. In other words, governance structures must align with characteristics of transactional activities, institutional environment must align with governance structures, and social norms and beliefs must conform to existing institutions. Misalignment will cause tensions and unnecessary costs within the system. These levels are linked, meaning that levels are dependent upon each other, and feedbacks between the lower and higher levels are relevant. The institutional approach of Williamson does not explicitly include biophysical factors as do the environmental sciences. However, NIE can be applied to the environment (see, for instance, Polman (2002) or Paavola and Adger (2005)).

\section{SYSTEM PROPERTIES OF ECOLOGICAL SCIENCES AND ECONOMIC SCIENCES}

We start by systematically discussing the system properties as modeled or postulated by both sciences. These properties include: boundaries, the smallest entity, the level of complexity, processes, and goal orientation within the system. Finally, we discuss the role of agents. Figure 1 gives an overview of the discussed system properties and presents how both archetypes of the ecological (landscape ecology) and economic (Walrasian economics) sciences have developed more integrating concepts of governance in their framework. Landscape ecology has transformed into socioecology, whereas NIE has developed from Walrasian economics.

\section{System boundaries}

Landscape ecology commonly defines the system and its boundaries in geographical terms. The system is delineated by a clear boundary referred to as the extent of the system. Within this delineation of systems, other subsystems can be identified that are expected to be hierarchically nested within the overall system. Examples are a river basin subdivided into sub-basins, which are further subdivided into local catchments. The choice of extent has a large effect on the results of analysis and the system complexity derived (Turner and O’Neill 1995).

Social-ecological systems are determined by the combined extent of spatial entity and actors (including institutions). Instead of an ecosystem, units are typically man made, e.g., countries, regions, parks, and farms. Gridded data is typically used in such a system to facilitate the merging of socioeconomic and geo-ecological data. The emphasis is usually on pattern description, analysis, and modeling (Carpenter et al. 2001, Lambin et al. 2001). In land-use systems, the role of extent is even more important (Kok and Veldkamp 2001), which is why we can observe national boundaries in 
Fig. 1. Comparison of the different system properties between ecological sciences and economic sciences.

\begin{tabular}{|c|c|c|c|c|c|}
\hline System property & $\begin{array}{l}\text { Landscape } \\
\text { Ecology }\end{array}$ & $\begin{array}{l}\text { Social } \\
\text { Ecological } \\
\text { Sciences }\end{array}$ & & New Institutional Economics & Walrasian Economics \\
\hline System boundaries & Extent & $\begin{array}{l}\text { Extent }+ \\
\text { Institutions }\end{array}$ & \multirow{6}{*}{ 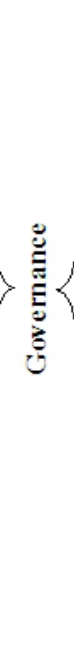 } & $\begin{array}{l}\text { (Non-contractual) relations in } \\
\text { noncompetitive settings are } \\
\text { possible }\end{array}$ & $\begin{array}{l}\text { Complete and enforceable } \\
\text { claims exchanged on } \\
\text { competitive markets }\end{array}$ \\
\hline Smallest entity & $\begin{array}{l}\text { Grain (resolution) } \\
\text { and/or species }\end{array}$ & $\begin{array}{l}\text { Grain } \\
\text { (resolution) }+ \\
\text { Agent }\end{array}$ & & Agent & Agent \\
\hline System quantification & $\begin{array}{l}\text { Pattern dynamics } \\
\text { and species } \\
\text { distribution } \\
\text { (spatio-temporal) }\end{array}$ & $\begin{array}{l}\text { Pattems (spatio- } \\
\text { temporal) }+ \\
\text { human agent } \\
\text { behavior }\end{array}$ & & $\begin{array}{l}\text { The economy as a self-contained } \\
\text { self-regulating entity: endogenous } \\
\text { preferences and endogenous } \\
\text { institutions }\end{array}$ & $\begin{array}{l}\text { The economy as a self-contained } \\
\text { self-regulating entity: exogenous } \\
\text { preferences and institutions }\end{array}$ \\
\hline System complexity & High & $\begin{array}{l}\text { High with a } \\
\text { predominately } \\
\text { nested hierarchy }\end{array}$ & & $\begin{array}{l}\text { High, network instead of } \\
\text { hierarchy }\end{array}$ & Complexity is limited \\
\hline System processes & $\begin{array}{l}\text { Multiple } \\
\text { interactions }\end{array}$ & $\begin{array}{l}\text { Multiple } \\
\text { interactions }\end{array}$ & & $\begin{array}{l}\text { Forward-looking individuals } \\
\text { dynamically update based on } \\
\text { incomplete information of system }\end{array}$ & $\begin{array}{l}\text { Forward-looking individuals } \\
\text { instantaneously update based on } \\
\text { knowledge of entire system }\end{array}$ \\
\hline $\begin{array}{l}\text { Agent behavior (e.g. } \\
\text { plant or animal species } \\
\text { or human) }\end{array}$ & Predictable & $\begin{array}{l}\text { Self-organized } \\
\text { with survival } \\
\text { goal }\end{array}$ & & $\begin{array}{l}\text { Self-regarding and other regarding } \\
\text { preferences defined over } \\
\text { outcomes. Goal oriented }\end{array}$ & $\begin{array}{l}\text { Self-regarding preferences } \\
\text { defined over outcomes. }\end{array}$ \\
\hline
\end{tabular}

remotely sensed data (Woodcock and Strahler 1987).

In a Walrasian economic framework, complete and enforceable claims are exchanged on competitive but well-connected markets. This implies that individuals' actions are based on far-sighted evaluations of their consequences, which, in turn, are based on preferences that are self-regarding and exogenously determined. In this context, social interactions are only contractual exchanges. In the Walrasian world, the concept of increasing returns to scale can be ignored, implying that the choice of extent has no relevance for the analysis or their outcomes. In economics, the system is defined in terms of actions (often reflected at markets that are equivalent in extent) and individual decisionmaking units (equivalent to grain). In Walrasian economic theory, spatial extent and spatial resolution seem to coincide (van der Veen and Otter 2003). Economists have paid more attention to the scale of time than the scale of space. New institutional economics adds non-competitive and non-contractual relations to the economics system. Coase (2005) argued that concentration on the price system resulted in neglect of other parts of the economic system. The costs of exchange, for instance, also depend on the institutions of a country (Coase 1998): its legal system, its political system, its social system, its educational system, its culture, and so on.

\section{Smallest entity}

The smallest spatiotemporal unit used in the ecological system description is either the species (assembly) or the smallest measured unit, such as a site or satellite image pixel. These smallest units are referred to as grains. Thus, from an ecological point of view, the system is described in terms of its extent and grain. Again, the choice of grain size has large implications for the processes that landscape ecologists can analyze and from which they can derive relevant ecological indicators. Grain sensitivity is especially high in systems where multiple processes interact and where the causality is unknown (Rastetter et al. 1992).

In a SES, the smallest entity is a combination of actor and grain. Very often this is a combination of the smallest spatial management unit (field, farm, 
or reserve) with its actor (farmer, manager). The actor is directly linked to spatial units, and his (or her) decisions connect the units managed. As a result, there are direct connectivities between agent and the grains used in the study.

Within Walrasian economics, the smallest entity is the decision-making agent and the products he produces or consumes. The concept of scale in economics is evident in the distinction between micro- and macroeconomics. Whereas microeconomics deals with individual consumers, producers, etc., and is concerned with the allocation of resources among these economic agents (Russell and Wilkinson 1979), macroeconomics is concerned with the way actions of consumers, producers, and public agencies determine economy-wide movements in output, unemployment, and inflation (Blanchard and Fischer 1989). Economic analyses are not that sensitive for the smallest entity. In economics, at the level of the agent, behavior can be projected on the basis of exogenous variables such as prices. At the aggregated level, prices are endogenous, and failure to specify them that way leads to significant errors in the projections of all other variables (Costanza et al. 1993, Norton 1995, van der Veen and Otter 2003). Various procedures have been suggested to address the aggregation problem encountered if micro and macro data are integrated (van Daal and Merkies 1984). Such an aggregation procedure is far from trivial in complex, non-linear, discontinuous systems (van der Veen and Otter 2003). The smallest entity in NIE remains the agent, without an extension to spatial units. However, a fundamental idea animating NIE is that transaction costs exist and necessarily influence the structure of institutions and the specific economic choices people make. The transaction costs, boundedly rational individuals, and the existence of opportunistic behavior are among the main features that distinguish it from the standard Walrasian point of view. Bounded rationality means that it will be costly for individuals to contemplate every contingency that might arise over the course of a transaction (Kreps 1990). Opportunistic behavior means that individuals are self-interested, with guile (Williamson 1985).

\section{System quantification}

Ecological systems are usually sampled by studying a certain number of sites or observations that are considered as representative for the studied system.
The system is usually quantified with explorative multivariate statistical techniques because ecological systems theory expects many different, often unknown, interactions of species and processes within the system (Pickett et al. 1989, Rastetter et al. 1992).

The advocated integration of socioeconomic and biophysical system data for SES quantification is complicated by the fact that it is very difficult to merge information from different source scales and levels. Very pragmatic approaches for spatial and temporal analysis have used artificial spatial units (grids) and arbitrary temporal units (growing season, months, years) to integrate data from different disciplinary sources (Veldkamp et al. 2001). One key scale property often ignored in such data-integration attempts is scale hierarchy (Wu and Li 2006), which is often clear in biophysical systems, especially ecosystems and other earth systems. Such a hierarchy is not valid for social systems because humans are part of a network. They not only have a direct role as consumer, member of a family, or part of a community, but also vote for a political party or support a NGO that might have a different, contradicting, role in the socioeconomic system. A critical issue that has emerged from all these scaling attempts in SES is that there is often a fundamental mismatch between the human and ecological system units.

In Walrasian economics, the system is postulated in a relatively simple way, allowing straightforward comparisons of different economic situations using "Pareto efficiencies" (Russell and Wilkinson 1979). An allocation in the economy is Pareto efficient if there is no alternative allocation that leaves everyone at least as well off and makes some people clearly better off. Institutions and preferences are considered as exogenous to the economic system. In NIE, preferences and institutions have become endogenous. No longer is the market the sole institution that is able to coordinate the market economy. Other coordination mechanisms such as authority become more central. Geography and ecological sciences quantify the system by diverse measurable processes and patterns. Economics quantifies the scarcity of goods and resources using the price. This may be straightforward for system products traded as commodities but is less straightforward with other ecosystem services available as common goods, such as biodiversity (Daily et al. 1997, Heywood 1995, Ostrom, 1990). 


\section{System complexity}

Landscape ecological systems are considered to be very complex, with many interacting different species across space and time, causing scalesensitive relationships (Pickett et al. 1989). Examples of relationships causing such complexity are: prey-predator interaction, symbiosis; interaction between resources such as nutrients and water gives specific patterns of vegetation and population dynamics of species. An important aspect of these interactions is that they operate at multiple scale levels, sometimes demonstrating surprising connectivities between systems in space and time (Kolasa 1989, Rastetter et al. 1992, Holling 2001). Examples are Saharan dust feeding the oceans and even the Amazonian rainforest and the impact of low concentrations of pesticides on amphibian development. The key concept of structural complexity in ecology is the existence of hierarchically nested levels within the system. Allen and Starr (1982) first conceptualized the Hierarchy Theory for ecology, which was later elaborated on by O'Neill (O'Neill et al. 1986, O'Neill 1988). An example of a nested hierarchy is the sequence: celltissue-leaf-branch-tree-stand-forest-ecoregion.

Land systems have a functional and structural complexity. Many different drivers and factors influence the system (functional complexity) and interact at many different levels (structural complexity), yielding often unforeseen outcomes and responses (Folke 2006). Land governance and policy are often seen as a human response to undesired effects and outcomes. In this context, governance and institutions are seen as adaptive behavior at different levels and are also referred to as multi-level governance (Marks 1993, Pierre 2000). In order to link humans to land it is relevant to have detailed information about land tenure. In this respect, the classical research by Ostrom about governing the commons (Ostrom 1990) illustrates what can happen if land tenure is not clear or existent. In landscape ecology and socioecology, system complexity is high.

The core assumptions of Walrasian economics are rational choices such as maximization, stable preferences, and equilibrium states (Vatn 2005). Rationality in Walrasian economics demands that preferences be complete, transitive, and continuous. Furthermore, in order to be termed rational, choices must be in accordance with the highest preference of the agent (Vatn 2005). As a logical consequence of this stereotypical behavior, preferences are treated as stable or as given. In such a system, there is no limit on the parties' ability to foresee contingencies, to write contracts, and to enforce them (Tirole 1999: 754). Thus, the system can be complex, with known agents that are able to handle the complete system. New institutional economics moves to more complex governance, requiring the introduction of added security features such as reducing incentive intensity and incurring added bureaucratic costs (Williamson 2000). This means that the move to complexity is done by more complex contract design including, for instance, the length of the contract, penalties for breach, and provisions for information disclosure. New institutional economics maintains an evolutionary perspective, which is a consequence of human nature and of the complexity of social systems composed of numerous agents whose behavior cannot be fully anticipated (Brousseau and Glachant 2008). In NIE, there is a need to develop ways to deal with complexity.

\section{System processes}

In landscape ecology, the focus is on processes of species interaction and species-environment interaction. Species distribution and patterns are linked to hypothesized processes, which are often not directly measured. As a result, the system is never in equilibrium but constantly striving toward such a state. The ecologists use the marble in the cup model to illustrate how a system state (marble) constantly changes as it moves within a stability landscape (cup). Due to the system complexity, multiple alternative steady states are possible with sometimes abrupt and irreversible state transitions. Consequently, a whole new branch of ecology has devoted its research to understanding system dynamics and complexity focused on issues of resilience and robustness (Holling 2001, Folke 2006, Fletcher and Hilbert 2007).

Within socioecology, many potential interacting system processes exist. The emphasis is usually on processes that interact between the social and ecological systems, e.g., a land-use system. Often, the emphasis is on how matter fluxes and flows, such as nutrients, energy, carbon, (Vitousek et al. 1997, Priess et al. 2001), or decision making (Parker et al. 2003, Verburg et al. 2006) can cause other types of connectivities. 
The hierarchical scale issue in ecology is an inherent challenge that cannot be solved easily in a socioeconomic context. It could well be the most important challenge when the aim is to develop policies and governance to mitigate scale effects, because social networks cannot be scaled.

In the Walrasian system, the assumed forwardlooking individuals can instantaneously update their knowledge of the entire system. The invisible hand of Adam Smith will automatically lead to the optimal solutions. In the absence of market failures, private land-use decisions are expected to be socially efficient, i.e., to maximize the net social return from use of the land.

From an institutional economic perspective, landuse decisions involve market failure and generate external costs (e.g., environmental pollution) or benefits (e.g., landscape attractiveness for tourism) that are not borne by the private parties making the land-use decisions. In such cases, the private net return from a given land use differs from the social net return, and private land-allocation decisions will not necessarily be socially efficient (Segerson et al. 2006: 79). The economic theory of externalities holds that the divergence between private and social costs and benefits is caused by a lack of appropriate defined (or enforced) property rights and jurisdiction. The basic solution is the internalization of the external effects into the economy, e.g., by correcting the market price for the external effect or to establish quotas. The scale of the external effect determines the level needed to organize this internalization. Although the concept of externality is widely used, various definitions still exist, and some of them may be imprecise, as observed by Mas-Collel et al. (1995).

\section{Agent behavior}

A system hierarchy implies a certain nested structure of process interactions. Within ecology, the system and species behavior is therefore considered to be, to some degree, predictable. That is why ecological models accept certain margins of uncertainty, and stochastic elements are often assumed. But the system as a whole is considered to have predictable behavior and patterns (Jørgensen 1994). So landscape ecology has limited information about the actors and processes and their interactions but considers the system within certain margins predictable.
Agents in a SES context consist not only of humans but include all types of species (plants, animals, etc). Within the broad definition, the social-ecological approach assumes self-organizing behavior. One important aspect of behavior is the adaptive component: all agents respond to each other and to their perceived changing environment (Folke et al. 2005). However, this adaptive component is still poorly addressed even in agent-based models (Parker et al. 2003) for land-use changes.

Within Walrasian economics, the focus is on agents and their behavior on markets, without a specific spatial dimension or interactions (van der Veen and Otter 2001, 2003). Consequently, Walrasian economics does not aim to predict real-world systems. Instead, the Walrasian approach represents economic behavior as the solution to a constrained optimization problem faced by a fully informed individual in a virtually institution-free environment (Bowles 2004). It deals with choices as it analyses the problem of allocating scarce resources to alternative uses. Many economic models are concerned with how this choice is made by the interaction of decision-making units-consumers, producers, and public agents - in a very constrained economic system (Russell and Wilkinson 1979). By using fundamental basic assumptions (e.g., disregarding transaction costs, assuming complete information and complete markets), Walrasian economic models bring complexity down to a manageable level (Vatn 2005). The agent description in NIE has become more behavioral and more institutional. This is because behavioral disciplines have contributed considerably to understanding human behavior (Gintis 2007) beyond profit-seeking rationality.

\section{BRIDGING SOCIAL-ECOLOGICAL SCIENCE AND NEW INSTITUTIONAL ECONOMICS}

Thus, we can observe two different approaches: on the one hand, ecology embracing complexity and making it a main focal point of research and, on the other hand, economics simplifying the system by making many assumptions and constraints in order to keep the system complexity manageable. Both streams - socioecology and NIE-now use agentbased modeling (ABM) to understand the role of agent decision making proceeding from these different starting points. The problem with agents is that they are not always directly linked to spatial 
units. It is still problematic to link ABM to spatial land patterns, although considerable progress has been made (Parker et al. 2003, Verburg and Veldkamp 2005, Filatova et al. 2009a, b).

When we compare the two paradigms of socialecological science and NIE, we can conclude that both have adapted to the need to be able to deal with real-world complexity. Both approaches recognize the need for a complex (system) approach, bridging the gap between landscape ecology and economics. Social-ecological science is founded in ecology theories whereas the NIE approach is well founded in economic theories. They both agree on the central role of agents and their decision making. Their main difference is in the (bounded) rational goal orientation of economic theories vs. the non-rational dynamics of socioecology of survival of the species. Socioecology is better linked to spatial scales and scale dynamics (issues like resilience and robustness) whereas the NIE has a better grip on the decision and transaction processes involved. Governance is an inherent part of NIE, but it is still an underdeveloped system response and process in socioecology. In the following section, we elaborate on governance as a way to bridge social-ecological science and NIE perspectives.

The discussed social-ecological science and NIE perspectives have quite an impact on the way coupled SES are described and considered to be managed. Economic science is goal oriented, aiming to influence human (actor) behavior; ecological science, however, is less goal oriented, aiming to manage "natural" biophysical processes and locations. These fundamentally different viewpoints have implications for solving scaling and linked governance issues, as will be illustrated in the case study on soil protection in the next section. When we compare the six evaluated system properties of Fig. 1, we can derive different system perspectives on governance.

Social-ecological system boundaries rarely match the governance units in The Netherlands; an exception is watershed management. Economic units seem to match governance units, with macroeconomics matching national government units and microeconomics matching household units. However, at other levels, this match does not occur, e.g., at the municipal level, and consumers and producers do not fit into the hierarchy of government. The smallest entity in a SES are agents in an environment, whereas economics primarily focuses on transactions, agents, and organizations with a poor spatial connection. Finally, agent behavior is also assumed to be different. In the social-ecological context, the agent is adaptive and tends to be self organized whereas, in NIE, the agent is assumed to be both self- and other-regarding.

In systems complexity, social-ecological science builds on nested hierarchy with self-organization whereas NIE goes from low complexity based in linear systems per scale level toward social networks that can have components of different levels. Social-ecological science tends to take the measured and modeled system dynamics as given and considers governance as a means to mitigate or "fix" unwanted effects of system change. New institutional economics, however, starts by organizing institutions and improving the description and organization of the institutional aspects. One could describe this as socialecological science seeing governance as a dominantly exogenous process whereas, in a NIE context, governance is an endogenous process in which governance structures depend on the underlying properties of the economic system. The combination of governance structures that will be most efficient in addressing a given coordination problem depends on the underlying technology and social facts that give rise to interdependence among actors. Institutions that govern a particular interaction will affect the preferences and beliefs of participants (Bowles 2004).

Another essential discriminating aspect is the different goal orientation of both approaches. The NIE goal is usually aiming for more effective economic optimal solutions by including more aspects of ecological systems. This is achieved by internalizing more factors that are considered relevant in order to facilitate better functioning governance structures, including markets. Socialecological science considers the SES as a complex dynamic system with many known and unknown functions and processes. Governance is only required when stakeholders or scientists identify unwanted environmental effects. This more response-oriented approach in a complex system context is referred to as adaptive governance (Folke et al. 2005, Lebel et al. 2006, Ostrom 2008). Consequently, approaches are advocated that allow the analysis of trade-offs and alternatives by using scenario and modeling approaches. The role of stakeholders is specifically important in defining alternative desirable futures and outcomes (van Vliet et al. 2009). 


\section{COMPARING SES AND NIE FOR A CASE STUDY ON SOIL PROTECTION}

Erosion and its consequences are interesting from both a social-ecological and socioeconomic point of view. As we will show, scaling issues are important for designing policies to deal with negative impacts of erosion. Soil protection (e.g., through control measures to reduce the risk of erosion) is an important goal of the EU soil strategy (European Commission 2006, Kuhlman et al. 2010). In Fig. 2, we attempt to apply the framework developed in the previous chapters to the EU soil strategy. Comparable to Cash et al. (2006), columns define "scales" such as the spatial, temporal, and analytical dimensions used to measure and study soil erosion. The rows are "levels" (string of beads) and defined as the units of analysis that are located at different positions on a scale. The first and second columns are, respectively, organized along a spatial scale and a jurisdictional scale. Figure 2 is limited to public governance; distinguishing a spatial scale and jurisdictional scale for analyzing governance is important. The analysis can be extended to private governance, e.g., chain management or consumer organizations. This extension would go beyond the purpose of the example-comparing socialecological and NIE perspectives on soil protection. National boundaries are of geopolitical and cultural nature and often have no environmental meaning. If one investigates natural amenities, it makes more sense to define regions from an environmental perspective, i.e., using environmental (hydrological, ecological) boundaries. Land use has environmental consequences that differ markedly depending on the pattern of remaining habitat and the size and proximity of disturbances to ecologically sensitive areas. (Geoghegan et al. 1997: 251). Alternatively to the spatial and jurisdictional scales, other scales could be used as a starting point for analysis; however, this goes beyond the scope of this paper. The third column represents elements of existing governance. Finally, the social-ecological and NIE columns on the righthand side of the figure represent the different issues and processes that are studied by these approaches.

The social-ecological science column shows that the erosion process is identically present at many scales (both erosion and sedimentation occur at the field level as well as at the higher level). The magnitude of the phenomenon changes along the scale axis. It is well documented that plot-level erosion rates can be an order of magnitude higher than those for whole catchments (Schaller et al. 2002). Possible ecological or economic instruments to combat erosion also change with scale. At the field level for individual farmers, the construction and maintenance of terraces or the conversion of arable land into pasture are suitable measures to reduce serious erosion. At the watershed level, more generic agricultural measures are more suitable, e.g., contour ploughing and the requirement to plant cover crops to prevent (moderate) erosion. In order to successfully combat erosion and prevent sedimentation of a lake in a region, a combination of measures at different levels is necessary: measures that are meant for farmers at the field level, measures for agriculture at the regional level, as well as measures for building sites and reforestation in all the non-field areas. Some of these measures go beyond the level of individual farmers and require some form of organization. In economics, agent or household behavior is related to the incentives received. Here, the distinction between on-site and off-site benefits is important. If the on-site benefits exceed the costs of a measure, the farmers will implement the measure voluntarily. However, if the combined on-site and off-site benefits exceed the costs, but the on-site benefits alone do not (Kuhlman et al. 2010), governance (economic) instruments are warranted to obtain the optimal situation for a region. Institutions are, therefore, important. The type of agent differs along the jurisdictional scale. At the municipal level, it concerns local organizations operating in social networks of stakeholders; at higher levels, organizations such as NGOs and governments (and interorganizational networks) become more important.

Governance solutions for the erosion problem will be different depending on the jurisdictional level. The higher the level in the jurisdiction column, the more formal is the governance structure. Governance and jurisdictions can either correspond or show mismatches in solving erosion problems. Governance structures influence (formally or informally) agents at every jurisdictional level. For instance, governance at the EU level affects pressure groups at the member state level as well as the decisions of farmers at the farm household level. However, the aggregate farmers' individual decisions affect the erosion at higher levels, including the European level.

The three scale challenges identified by Cash et al. (2006) are also eminent in the erosion problem. Ignorance is the fact that, although the problem is 
Fig. 2. Scaling and governance issues in the European Union soil strategy.

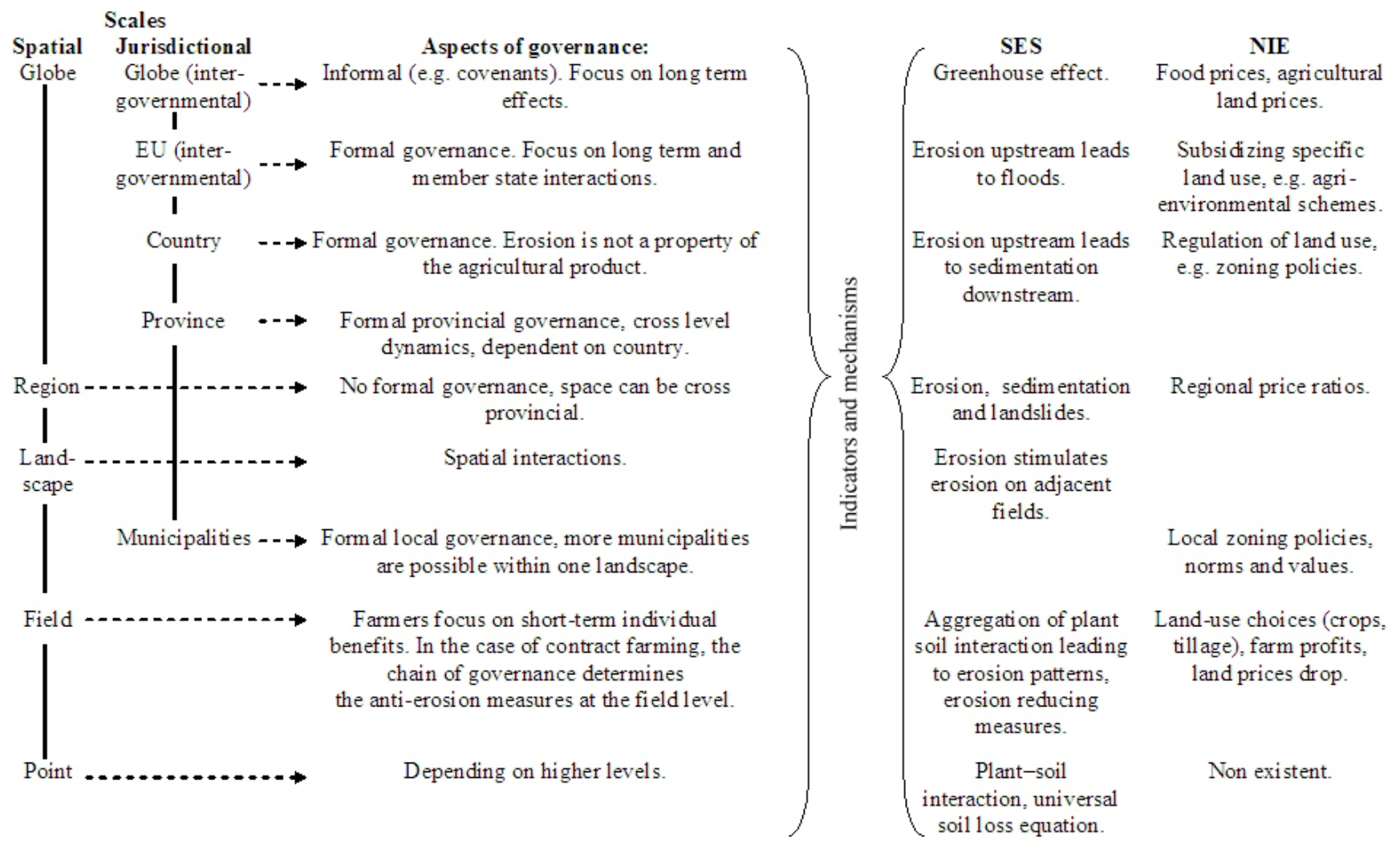

felt at all scales, the solution using soil-conserving measures is predominantly at the field, farm, and community scales. Mismatch is related to the fact that the jurisdictional levels do not coincide with the erosion processes. Erosion leading to sedimentation in a particular river concerns the practices in the entire river basin, which may span the territory of more than one country. The reverse also applies, supra-national regional policies affect not only the targeted river basins but also regions outside them. Kuhlman et al. (2010) conclude that soil-preserving measures at the field level targeting farmers (stimulated by subsidies from a higher jurisdictional level) reduce sedimentation at higher spatial levels. This is an example of cross-scale dynamics. Plurality is present because there is not one single best scale or level to solve the erosion problem; erosion can be best mitigated by a combined multi-scale approach (Veldkamp et al. 2001). Connecting different scales is important for solving erosion problems (and enhancing sustainable agricultural production), not only in Europe but also in other areas of the world.

Addressing these challenges can potentially contribute to savings in transactions costs (related to governance) that can be analyzed by scrutinizing the costs and benefits of governance at different levels. An important issue is the link between policies at different levels (country vs. provincial) and soil protection at, for instance, the field level. This issue relates to the debate on central vs. noncentral government. Benefits can be assessed in terms of the adequacy of the rule with preferences and needs of agents. Costs are linked to the resources earmarked by agents for solving coordination problems at a given "level" of governance (see Brousseau and Raynaud 2007). Thus, it can be concluded that there is not one uniform, generally applicable, governance solution to combat erosion 
at multiple scales and levels. A practical consequence for policy making is that flexibility in the use of different governance structures and measures at different scale levels is required to address these challenges. Taking into account complexity, discontinuity, and non-linearity of systems in a more systematic way can help to develop effective policies. The consequence is that combining SES and governance structures suggested by social-ecological science and NIE can lead to soil protection at different levels in which public and private governance is combined.

\section{TOWARD A NEW RESEARCH AGENDA}

Linking scaling to governance is an important issue for the improvement of current environmental management and policies. The notion of different scales (e.g., temporal and spatial) and levels across these scales is central. We started from the disciplinary paradigms of landscape ecological sciences and Walrasian economics. Both disciplines are more-or-less aware of the scaling issues involved and developed over time into the science fields of social-ecological science and NIE.

We propose that a combined socioecology-NIE scientific approach can lead to more integrated solutions for the scaling governance problem. By combining the two approaches, which have already been converging over the last decade, we hope to bridge the gap between multi-scale system and multi-level governance research. Future research will need to focus on how to link the different system properties used by both disciplines. After a consultation process, we identified the following research themes:

1. How to combine spatial properties such as extent and grain with the economic units of market and agent. We suggest that a thorough social-ecological type of analysis of NIE systems and vice versa might enlighten us as to how to combine them effectively. The use of gridded data in order to merge socioeconomic and geoecological data could be a means to describe NIE systems and their spatial extent. The way governance is studied in NIE can contribute to an integral analysis of a SES in which governance of the system is composed of different governance structures, where the arguments developed in NIE will help define the extent of the system.
2. How to combine the different governance instruments proposed by both perspectives. Here, a more concise description and definition of typical social-ecological governance might be the way forward. Social-ecological science could contribute to NIE for the analysis of complex economic systems. Functional and structural complexity as studied in social-ecological science can help NIE make the arguments for institutional complexity more clear.

3. How to communicate the different scaling perspectives (hierarchy vs. no hierarchy) and meanings to policy makers and other stakeholders. Here, issues such as visualizing complex system dynamics and multi-scale trade-offs might be a fruitful way ahead. The inclusion of external effects in socialecological science could be beneficial. First experiments with problem and scenario visualization indicate that visualizing the spatial and temporal dimensions of problems and solutions changes the policy makers' perspective (Beers et al. 2010)

4. How to deal with the non-equilibrium conditions in the real world and the socialecological and NIE perspectives. Here, further elaboration of temporal dynamics in both NIE and social-ecological approaches might give us more insights (see Apeldoorn et al. (2010), this issue). The understanding of non-equilibrium conditions will help us understand systems that will be relevant to both disciplines. System changes occur when thresholds are passed, and factors contributing to this are often combinations of socialecological and economic nature. A research question could be whether governance is a way to prevent or encourage system changes, or whether governance is but one of the contributing factors.

It is important to realize that the dynamics governing a system provide an account of its outof-equilibrium behavior and, thus, not only help in the process of equilibrium selection but also in studying the response to shocks and other problems for which the standard comparative static method is ill suited (Bowles 2004). Finally, from a governance perspective, it is relevant to note that our analysis has clearly demonstrated that scale matters and that 
recognizing different scales and levels is a necessity in environmental policy and governance. It is actually the role of framing, sense making, and meaning of knowledge in policy making that can help implement solutions effectively for the challenges regarding ignorance of cross-level and cross-scale interactions. The mismatch of human institutions with the biophysical scale of resources in space and time might not be the problem, but rather the notion that there is no single, correct or best solution. Science will not provide answers but only options and trade-offs to choose from (Giller et al. 2008). Currently, different disciplines inform policy makers quite differently, with a tendency for the economic approaches to provide answers and the ecological sciences to provide problems. Fortunately, we are already observing a convergence of both disciplines toward a more balanced analysis and more realistic presentations of governance options.

\section{CONCLUSIONS}

Significant progress can be made in effective governance by linking ecological and economic system perspectives. Whereas social-ecological science tends to focus on adaptive behavior and aspects of spatial ecological data, NIE focuses more on levels in institutional scales and temporal dimensions. Consequently, both disciplines perceive different scaling challenges while aiming at a similar improvement in effective governance. We propose that future research needs to focus on four themes: (1) How to combine spatial properties such as extent and grain with the economic units of market and agent; (2) How to combine the different governance instruments proposed by both perspectives; (3) How to communicate the different scaling perspectives (hierarchy vs. no hierarchy) and meanings to policy makers and other stakeholders; and (4) How to deal with the nonequilibrium conditions in the real world and the disciplinary perspectives.

Responses to this article can be read online at: http://www.ecologyandsociety.org/voll6/iss 1/art1/responses/

\section{Acknowledgments:}

This paper was written in the context of the IP/OP "Scaling and Governance" Research Program, which has been spearheaded by Wageningen University and Research Center (Wageningen UR) and was funded by the strategic research program "Sustainable spatial development of ecosystems, landscapes, seas and regions" of the Dutch Ministry of Economic Affairs, Agriculture and Innovation and the IP/OP.

\section{LITERATURE CITED}

Allen, T. F. H., and T. B. Starr. 1982. Hierarchy; perspectives for ecological complexity. The University of Chicago Press, Chicago, Illinois, USA.

Anderies, J. M., M. A. Janssen, and E. Ostrom. 2004. A framework to analyze the robustness of socialecological systems from an institutional perspective. Ecology and Society 9(1): 18. [online] URL: http:// www.ecologyandsociety.org/vol9/iss1/art18.

Beers, P. J., A. Veldkamp, F. Hermans, D. van Apeldoorn, J. M. Vervoort, and K. Kok. 2010. Future sustainability and images. Futures: in press. DOI: 10.1016/j.futures.2010.04.017.

Berkes F., T. P. Hughes, R. S. Steneck, J. A. Wilson, D. R. Bellwood, B. Crona, C. Folke L. H. Gunderson, H. M. Leslie, J. Norberg, M. Nyström, P. Olsson, H. Österblom, M. Scheffer, and B. Worm. 2009. Globalization, roving bandits, and marine resources. Science 17((5767):1557-1558.

Blanchard, O. J., and S. Fischer. 1989. Lectures on macroeconomics. MIT Press, Cambridge, Massachusetts, USA and London, UK.

Boddiger, D. 2007. Boosting biofuel crops could threaten food security. The Lancet 370(9591):923924. 
Bowles, S. 2004. Microeconomics: behavior, institutions and evolution. Princeton University Press, Princeton, New Jersey, USA.

Brand, F. S., and K. Jax. 2007. Focusing the meaning(s) of resilience: resilience as a descriptive concept and a boundary object. Ecology and Society 12(1): 23. [online] URL: http://www.ecologyandso ciety.org/vol12/iss1/art23/.

Brousseau, E., and J. M. Glachant. 2008. A road map for the guide book. Pages xxi-lvii in E. Brousseau and J. M. Glachant. New institutional economics; a guidebook. Cambridge University Press, Cambridge, UK.

Brousseau, E., and E. Raynaud. 2007. The economics of multilevel governance. Paper presented at the 2006 ISNIE Conference. University of Colorado, Boulder, Colorado, USA.

Carpenter, S., B. Walker, J. M. Anderies, and N. Abel. 2001. From metaphor to measurement: resilience of what to what? Ecosystems 4:765-781.

Cash, D. W., W. N. Adger, F. Berkes, P. Garden, L. Lebel, P. Olsson, L. Pritchards, and O. Young. 2006. Scale and cross-scale dynamics: governance and information in a multi-level world. Ecology and Society 11(2): 8. [online] URL: http://www.ecology andsociety.org/vol11/iss2/art8.

Coase, R. H. 1978. Economics and contiguous disciplines. The Journal of Legal Studies 7(2):201211.

Coase, R. H. 1998. The new institutional economics. The American Economic Review 88(2):72-74.

Coase, R. H. 2005. The institutional structure of production. Pages 31-39 in C. Ménard and M. M. Shirley, editors. Handbook of New Institutional Economics. Springer, Berlin, Germany, Dordrecht, The Netherlands, and Boston and New York, New York, USA.

Costanza, R., L. Wainger, C. Folke, K. G. Mäler. 1993. Modeling complex ecological economic systems. BioScience 43(8):545-555.

Costanza, R., F. Andrade, P. Antunes, M. van den Belt, D. Boersma, D. F. Boesch, F. Catarino, S. Hanna, K. Limburg, B. Low, M. Molitor, G. Pereira,
S. Rayner, R. Santos, J. Wilson, and M. Young. 1999. Ecological economics and sustainable governance of the oceans. Ecological Economics 31:171-188.

Cumming G. S., D. H. M. Cumming and C. L. Redman. 2006. Scale mismatches in socioecological systems: causes, consequences and solutions. Ecology and Society 11(1): 14. [online] URL: http://www.ecologyandsociety.org/vol11/iss1/ art14/.

Daily, G. C., S. Alexander, P. R. Ehrlich, L. Goulder, J. Lubchenco, P. A. Matson, H. A. Mooney, S. Postel, S. H. Schneider, D. Tilman, and G. M. Woodwell. 1997. Ecosystem services: benefits supplied to human societies by natural ecosystems. Issues in Ecology 2:1-18.

Dalgaard, T., N. J. Hutchings, and J. R. Porter. 2003. Agroecology, scaling and interdisciplinarity. Agriculture, Ecosystems and Environment 100:3951 .

Davis, L. E., and D. C. North. 1971. Institutional change and American economic growth. Cambridge University Press, Cambridge, UK.

De Koning, G. H. J., A. Veldkamp, and L. O. Fresco. 1998. Land use in Ecuador: a statistical analysis at different aggregation levels. Agriculture, Ecosystems and Environment 70:231-247.

Dixit, A. K. 2003. On modes of economic governance. Econometrica 71(2):449-481.

Dixit, A. K. 2004. Lawlessness and economics; alternative modes of governance. Princeton University Press, Princeton, New Jersey, USA and Oxford, UK.

European Commission. 2006. Proposal for a directive of the European Parliament and of the Council establishing a framework for the protection of soil and amending directive 2004/35/EC. Brussels, 22-9-2006. COM(2006)232 final.

Filatova, T., D. Parker, and A. van der Veen. 2009a. Agent-based urban land markets: agent's pricing behavior, land prices and urban land use change. Journal of Artificial Societies and Social Simulation 12(1):3. 
Filatova, T., A. van der Veen, and D. C. Parker. 2009b. Land market interactions between heterogeneous agents in a heterogeneous landscape: tracing the macro-scale affects of individual tradeoffs between environmental amenities and disamenities. Canadian Journal of Agricultural Economics 57(4):431-457.

Fletcher, C. S., and D. W. Hilbert. 2007. Resilience in landscape exploitation systems. Ecological Modelling 201:440-452.

Folke, C. 2006. Resilience: the emergence of a perspective for social-ecological systems analyses. Global Environmental Change 16:253-267.

Folke, C., T. Hahn, P. Olsson, and J. Norberg. 2005. Adaptive governance of social-ecological systems. Annual Review of Environmental Resources 30:441-473.

Furubotn, E. G., and R. Richter. 1997. Institutional and economic theory: the contribution of the new institutional economics. University of Michigan Press, Ann Arbor, Michigan, USA.

Geoghegan, J., L. Pritchard, Jr., Y. OgnavaHimmelberger, R. R. Chowdhury, S. Sanderson, II, and B. L. Turner. 1998. Socializing the pixel and pixelizing the social in land-use/cover change. Pages 51-69 in D. Liverman, E. F. Moran, R. R. Rindfuss, and P. C. Stern, editors. People and pixels. Committee on the Human Dimensions of Global Environmental Change, National Research Council, National Academy of Science Press, Washington, D.C., USA.

Geoghegan, J., L. Waineger, and N. Bockstael. 1997. Spatial landscape indices in a hedonic framework: an ecological economics analysis using GIS. Ecological Economics 23:251-264.

Gibson, C., E. Ostrom, and T.-K. Ahn. 2000. The concept of scale and the human dimensions of global change: a survey. Ecological Economics 32:217239.

Giller, K. E., C. Leeuwis, J. A. Anderson, W. Andriesse, A. Brouwer, P. Frost, P. Hebinck, I. Heitkönig, M. K. Ittersum, N. Koning, R. Ruben, M. Slingerland, H. Udo, A. Veldkamp C. van de Vijver, M. T. van Wijk, and P. Windmeijer. 2008. Competing claims of natural resources: what is the role of science. Ecology and Society 13(2): 34. [online] URL: http://www.ecologyandsociety.org/vol13/ iss $2 / \operatorname{art} 34 /$.

Gintis, H. 2007. A framework for the unification of the behavioral sciences. Behavioral and Brain Sciences 30:1-61.

Global Land Project (GLP). 2005. Global land project: science plan and implementation strategy. IGBP Report 53, IHDP Report No. 19. IGBP Secretariat, Stockholm, Sweden.

Goudsblom B., and J. Vries. 2002. Towards a historical view of humanity and the biosphere. Pages 15-20 in B. Goudsblom and J. Vries. Mappae mundi; humans and their habitats in a long term socio-ecological perspective, myths, maps and models. Amsterdam University Press, Amsterdam, The Netherlands.

Heywood, V. H. 1995. Global biodiversity assessment. United Nations Environment Programme. Cambridge University Press, Cambridge, UK.

Holling, C. S. 2001. Understanding the complexity of economic, ecological, and social systems. Ecosystems 4:390-405.

Jaeger, C. C., and R. Tol. 2003. Sustainability and economics: a matter of scale? Pages 107-124 in J. Rotmans and D. S. Rothman, editors. Scaling in integrated assessment. Swets and Zeilinger Publishers, Lisse, The Netherlands.

Janssen, M. A., and J. M. Anderies. 2007. Robustness trade-offs in social-ecological systems. International Journal of the Commons 1:43-65.

Joskow, P. L. 2008. Introduction to new institutional economics: a report card. Pages 1-19 in E. Brousseau and J. M. Glachant. New institutional economics; a guidebook. Cambridge University Press, Cambridge, UK.

Jørgensen, S. E., editor. 1994. Fundamentals of ecological modelling. Developments in Environmental Modelling 19:1-628.

Kinzig, A. P., P. Ryan, M. Etienne, H. Allison, T. Elmqvist and B. H. Walker. 2006. Resilience and regime shifts: assessing cascading effects. Ecology and Society 11 (1): 20. [online] URL: http://www.e cologyandsociety.org/vol11/iss1/art20/. 
Kok, K. and A. Veldkamp. 2001. Evaluating impact of spatial scales on land use pattern analysis in Central America. Agriculture Ecosystems and Environment 85:205-222.

Kolasa, J. 1989. Ecological systems in hierarchical perspective: breaks in community structure and other consequences. Ecology 70:36-47.

Kreps, D. M. 1990. A course in microeconomic theory. Harvester Wheatsheaf, New York, New York, USA.

Kuhlman, T., S. Reinhard, and A. Gaaff. 2010. Estimating the costs and benefits of soil conservation in Europe. Land Use Policy 27(1):2232.

Lambin, E. F., and H. Geist, editors. 2006. Landuse and land-cover change. Local processes and global impacts. Springer IGBP Series, Berlin, Heidelberg, Germany.

Lambin, E. F., B. L. Turner, H. J. Geist, S. B. Agbola, A. Angelsen, J. W. Bruce, O. T. Coomes, R. Dirzo, G. Fischer, C. Folke, P. S. George, K. Homewood, J. Imbernon, R. Leemans, X. Li, E. F. Moran, M. Mortimore, P. S. Ramakrishnan, J. F. Richards, H. Skånes, W. Steffen, G. D. Stone, U. Svedin, A. Veldkamp, C. Vogel, and J. Xu. 2001. The causes of land-use and land-cover change: moving beyond myths. Global Environmental Change 11:261-26.

Lebel, L., J. M. Anderies, B. Campbell, C. Folke, S. Hatfield-Dodds, T. P. Hughes, and J. Wilson. 2006. Governance and the capacity to manage resilience in regional social-ecological systems. Ecology and Society 11(1): 19. [online] URL: http: //www.ecologyandsociety.org/vol11/iss1/art19/.

Marks, G. 1993. Structural policy and multilevel governance in the EU. Pages 391-341 in A. Cafruny and G. Rosenthal, editors. The state of the European Community. Lynne Rienner, Boulder, Colorado, USA.

Mas-Collel, A., M. D. Whinston, and J. R. Green. 1995. Microeconomic theory. Oxford University Press, Oxford, UK.

Ménard, C. 1995. Markets as institutions versus organizations as markets? Disentangling some fundamental concepts. Journal of Economic Behaviour and Organization 28:161-182.

Ménard, C., and M. M. Shirley. 2005. Introduction. Pages 1-18 in C. Ménard and M. M. Shirley, editors. Handbook of new institutional economics. Springer, Dordrecht, The Netherlands.

Medema, S. 1995. Ronald Coase on economics and economic method. History of Economics Review 24:1-22.

North, D. C. 2000. Understanding institutions. Pages 7-10 in C. Ménard, editor. Institutions, contracts and organizations; perspectives from new institutional economics. Edward Elgar, Cheltenham, UK and Northampton, Massachusetts, USA.

Norton, R. D. 1995. Response to section C. Pages 237-247 in J. Bouma, A. Kuyvenhoven, B. A. M. Bouman, J. C. Luyten, and H. G. Zandstra, editors. Eco-regional approaches for sustainable land use and food production. Systems Approaches for Sustainable Agricultural Development, Volume 4. Kluwer, Dordrecht, The Netherlands.

O'Neill, R. V. 1988. Hierarchy theory and global change. Pages 29-45 in T. Rosswall, R. G. Woodmansee, and P. G. Risser, editors. Scales and global change. Spatial and temporal variability in biospheric and geospheric processes. SCOPE 35, Wiley, Chichester, UK.

O’Neill, R. V., D. L. DeAngelis, J. B. Waide, and T. F. H. Allen. 1986. A hierarchical concept of ecosystems. Monographs in Population Biology 23. Princeton University Press, Princeton, New Jersey, USA.

Ostrom, E. 1990. Governing the commons. The evolution of institutions for collective action. Cambridge University Press, New York, New York, USA.

Ostrom, E. 2008. Institutions and the environment. The economic analysis of institutions. Economic Affairs 28(3):24-31.

Ostrom, E., M. A. Janssen, and J. M. Anderies. 2007. Going beyond panaceas special feature: going beyond panaceas. Proceedings of the National Academy of Science 104:15176-15178. 
Paavola, J., and W. N. Adger. 2005. Institutional ecological economics. Ecological Economics 53 (3):353-368.

Parker, D., S. Manson, M. A. Janssen M. Hoffmann, and P. Deadman. 2003. Multi-agent systems for the simulation of land use and land cover change: a review. Annals of the Association of American Geographers 93(2):314-337.

Peterson, D. L., and V. T. Parker, editors. 1998. Ecological scale: theory and applications. Columbia University Press, New York, New York, USA.

Pickett, S. T. A., J. Kolasa, , J. J. Armesto, and S. L. Collins. 1989. The ecological concept of disturbance and its expression at various hierarchical levels. Oikos 54:129-136.

Pierre, J. 2000. Introduction: understanding governance. Pages 1-10 in J. Pierre, editor. Debating governance; authority, steering and democracy. Oxford University Press, Oxford, UK.

Polman, N. B. P. 2002. Institutional economics analysis of contractual arrangements; managing wildlife and landscape on Dutch farms. Dissertation, Wageningen University, Wageningen, The Netherlands.

Priess, J. A., G. H. J. de Koning, and A. Veldkamp. 2001. Assessment of interactions between land use change and carbon and nutrient fluxes in Ecuador. Agriculture, Ecosystems and Environment 85:269279.

Rastetter, E. B., A. W. King, B. J. Cosby, G. M. Horberger, R. V. O'Neill, and J. E. Hobbie. 1992. Aggregating fine-scale ecological knowledge to model coarser-scale attributes of ecosystems. Ecological Applications 21:55-70.

Rhodes, R. A. W. 2007. Understanding governance: ten years on; peripheral vision. Organization Studies 28:1243-1264.

Russell, R., and M. Wilkinson. 1979. Microeconomics: a synthesis of modern and neoclassical theory. Wiley, New York, New York, USA.

Schaller, M., F. von Blanckenburg, A. Veldkamp, L. A. Tebbens, N. Hovius, and P. W. Kubik. 2002. A $30000 \mathrm{yr}$ record of erosion rates from cosmogenic
${ }^{10} \mathrm{Be}$ in Middle European river terraces. Earth and Planetary Science Letters 204(1-2):307-320.

Segerson, K., A. J. Plantinga, and E. G. Irwin. 2006. Theoretical background. Pages 79-112 in K. P. Bell, K. J. Boyle, and J. Rubin, editors. Economics of rural land-use. Ashgate Publishing, Farnham, UK.

Tirole, J. 1999. Incomplete contracts: where do we stand? Econometrica 67(4):741-781.

Turner, B. L. II, E. F. Lambin, and A. Reenberg. 2007. Land change science special feature: the emergence of land change science for global environmental change and sustainability, Proceedings of the National Academy of Science 104(52):2066620671.

Turner, M. G., and R. V. O’Neill. 1994. Exploring aggregation in space and time. Pages 194-208 in C. G. Jones and J. H. Lawton, editors. Linking species and ecosystems. Chapmann and Hall, New York, New York, USA.

van Daal, J., and H. Q. M. Merkies. 1984. Aggregation in economic research: from individual to macro relations. Reidel Publishing Company, Dordrecht, The Netherlands.

van der Veen, A., and H. S. Otter. 2001. Land use changes in regional economic theory. Environmental Modeling and Assessment 6:145-150.

van der Veen, A., and H. Otter. 2003. Scales in economic theory. Pages 125-138 in J. Rotmans and D. S. Rothman, editors. Scaling in integrated assessment. Swets and Zeilinger Publishers, Lisse, The Netherlands.

van Vliet, M., K. Kok, and A. Veldkamp. 2009. Linking stakeholders and modellers in scenario studies: the use of fuzzy cognitive maps as a communication and learning tool. Futures 42(1):114. doi:10.1016/j.futures.2009.08.005.

Vatn, A. 2005. Rationality, institutions and environmental policy. Ecologcal Economics 55:203-217.

Veldkamp, A. 2009. Investigating land dynamics: future research perspectives. Journal of Land Use Science 4:7-15. 
Veldkamp, A., K. Kok, G. H. J. de Koning, P. H. Verburg, J. Priess, and A. R. Bergsma. 2001. The need for multi-scale approaches in spatial specific land use change modelling. Environmental Modeling and Assessment 6:111-121.

Verburg, P. H., M. D. A. Rounsevell, and A. Veldkamp. 2006. Scenario based studies of future land use in Europe. Agriculture, Ecosystems and Environment 114:1-6.

Verburg, P. H., and A. Veldkamp. 2005. Editorial: spatial modeling to explore land use dynamics. International Journal of GIS 19:99-102.

Vitousek, P. M., J. D. Aber, R. W. Howarth, G. E. Likens, P. A. Matson, D. W. Schindler, W. H. Schlesinger, and D. G. Tilman. 1997. Human alteration of the global nitrogen cycle: Ssources and consequences. Ecological Applications 7:737-750.

Walker, B., L. Gunderson, A. Kinzig, C. Folke, S. Carpenter, and L. Schultz. 2006. A handful of heuristics and some propositions for understanding resilience in social-ecological systems. Ecology and Society 11(1): 13. [online] URL: http://www.e cologyandsociety.org/vol11/iss1/art13.

Westley, F., S. R. Carpenter, W. Brock, C. S. Holling and L. H. Gunderson. 2002. Why systems of people and nature are not just social and ecological systems. Pages 103-120 in L. H. Gunderson and C. S. Holling, editors. Panarchy: understanding transformations in systems of humans and nature. Island Press, Washington, D. C., USA.

Williamson, O. E. 1985. The economic institutions of capitalism. The Free Press, New York, New York, USA.

Williamson, O. E. 1996. The mechanisms of governance. University Press, Oxford, New York, New York, USA.

Williamson, O. E. 1998. Transaction cost economics: how it works; where it is headed. $D e$ Economist 146(1):23-58.

Williamson, O. E. 2000. The new institutional economics: taking stock, looking ahead. Journal of Economic Literature XXXVIII: 595-613.
Woodcock, C. E., and A. H. Strahler. 1987. The factor of scale in remote sensing. Remote Sensing of Environment 21(3):311-332.

$\mathrm{Wu}$, J., and H. Li. 2006. Concepts of scale and scaling. Pages 1-13 in J. Wu, K. B. Jones, H. Li, and O. L. Loucks, editors. Scaling and uncertainty analysis in ecology: methods and applications. Springer, Dordrecht, The Netherlands. 